J. Lake Sci. (湖泊科学), 2019, 31(3): 714-723

DOI 10. 18307/2019. 0310

(c) 2019 by Journal of Lake Sciences

\title{
巢湖流域双桥河底泥疏浚对浮游甲壳动物群落结构的影响
}

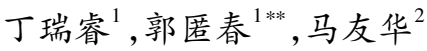 \\ ( 1 : 安徽农业大学资源与环境学院, 合肥 230036) \\ ( 2 : 安徽农业大学新农村研究院, 合肥 230036)
}

\begin{abstract}
摘 要: 为研究河流底泥疏浚工程对富营养化河流水生生态系统的影响,选取巢湖双桥河开展为期一年的河流生态监测 与调查, 对比分析了巢湖双桥河疏浚前和疏浚后的水质指标、浮游甲壳动物群落结构及生物多样性指数. 研究发现: 底泥 疏浚后双桥河水质得到明显改善, 其中氮、磷营养盐分别削减 $48.09 \%$ 和 $19.09 \%$; 底泥疏浚对浮游甲壳动物群落结构影响 显著, 疏浚后浮游甲壳动物生物量从 $1.86 \mathrm{mg} / \mathrm{L}$ 下降到 $0.25 \mathrm{mg} / \mathrm{L}$, 下降了 $86.40 \%$; 疏浚后生物多样性指数高于疏浚前, 且 受季节影响较大; 浮游甲壳动物与水环境因子相关性研究发现: $\mathrm{pH} 、$ 温度、铵态氮、硝态氮、可溶性氮、总氮和氮磷比对浮 游甲壳动物总生物量均有极显著影响. 研究结果表明, 河流底泥疏浚工程能显著削减水体中氮、磷营养盐, 并从一定程度 上改善河流浮游甲壳动物群落结构, 促进河流水生生态系统向健康、安全的方向发展. 因此, 对于双桥河这种受城市外源 污染影响较大的城市污染型河流, 在削减外源营养盐特别是氮输人的条件下, 实施底泥疏浚工程可以促进其水生生态系 统的修复.
\end{abstract}

关键词: 双桥河; 底泥疏浚; 水质指标; 浮游甲壳动物; 群落结构;生物多样性指数

\section{Effects of sediment dredging on crustacean zooplankton community of Shuangqiao River in Chaohu Basin}

\author{
DING Ruirui $^{1}$, GUO Nichun ${ }^{1 * *} \&$ MA Youhua ${ }^{2}$ \\ (1: College of Resources and Environment, Anhui Agricultural University, Hefei 230036, P.R.China) \\ (2: New Rural Development Research Institute, Anhui Agricultural University, Hefei 230036, P.R.China)
}

\begin{abstract}
The effects of sediment dredging events on the aquatic ecosystem of Shuangqiao River in Chaohu Basin were researched in the present study, a one-year investigation on the aquatic ecosystem operated in the river. The water quality, the crustacean zooplankton community and the biodiversity index were compared and analyzed pre- with post-dredging. Our results indicated that: The sediment dredging events improved the water quality of Shuangqiao River significantly, and the concentration of nitrogen ( N) and phosphorus (P) decreased by $48.09 \%$ and $19.09 \%$, respectively. The sediment dredging events had a significant influence on the crustacean zooplankton community, the biomass of crustacean zooplankton decreased from $1.86 \mathrm{mg} / \mathrm{L}$ to $0.25 \mathrm{mg} / \mathrm{L}$, which declined by $86.40 \%$. The biodiversity index was mainly affected by sediment dredging and season. There's significant relationships between crustacean zooplankton and environment factors: $\mathrm{pH}$, temperature, ammonium, nitrate, total dissolved nitrogen, total nitrogen and nitrogen: phosphorus ratio were positive to the biomass of crustacean zooplankton. Our results suggested that the sediment dredging would reduce the internal nutrients of river significantly. Furthermore, the sediment dredging events had a significant effect on the crustacean zooplankton community. The aquatic ecosystems of river would be healthy and safety by the operation of sediment dredging. Therefore, the sediment dredging would be beneficial for the aquatic ecosystem, while the eutrophication management of river was not only attribute to the removal of urban external pollution, but also to the exogenous pollution, especially for the reduction of $\mathrm{N}$ input.
\end{abstract}

Keywords: Shuangqiao River; sediment dredging events; water quality; crustacean zooplankton; community structure;

* 国家自然科学基金项目 (31300395) 和中国科学院南京地理与湖泊研究所湖泊与环境国家重点实验室开放基金项 目 (2014SKL008) 联合资助. 2018-08-13 收稿;2018-11-17 收修改稿. 丁瑞睿 (1995 ), 女, 硕士研究生; E-mail: realdrr@163.com.

** 通信作者;E-mail: guonichun@ ahau.edu.cn. 
biodiversity index

河流内源沉积底泥中氮、磷营养盐的释放是造成水体富营养化和藻类水华暴发的重要原因之一 ${ }^{[1]}$. 一 般认为, 底泥疏浚是削减水体内源负荷最为直接和有效的方法 ${ }^{[2-4]}$, 其原理是通过疏挖富含营养盐的底泥以 削减水体内污染源, 从而实现水体富营养化治理和蓝藻水华控制 ${ }^{[5]}$. 我国长春南湖 ${ }^{[6]}$ 、宁波月湖 ${ }^{[7]}$ 、杭州西 湖 $^{[8]}$ 以及瑞士的 Trehörningen 湖 ${ }^{[9]}$ 、荷兰的 Zierikzee 湾 ${ }^{[10]}$ 等国内外多处水域已进行底泥疏浚工程. 目前, 国 内对于底泥疏浚的研究主要集中水环境容量和水体水质的改善上,对河流水生生态系统结构和功能的影响 尚有待进一步研究 ${ }^{[5,11]}$. 浮游甲壳动物是水生生态系统的重要组成部分, 广泛分布于河流的各区段,种类 多、数量大, 且对水环境的变化极为敏感, 可以作为水质变化的重要指示动物 ${ }^{[12]}$. 同时, 作为水生生物常见 的优势种群, 浮游甲壳动物承接着水体初级生产者和高级消费者 ${ }^{[13-15]}$, 在河流生态系统的结构和功能中发 挥重要的作用 ${ }^{[11,16-17]}$.

巢湖双桥河位于巢湖北侧, 是主要人湖的 10 条河流之一. 由于流域内污水管网不完善和大量企事业单 位污水直接排放人河, 流域内氮、磷营养盐负荷常年超标, 是巢湖的一个重要污染源. 双桥河人湖口距巢湖 市自来水厂取水口仅 $500 \mathrm{~m}$, 其污染对市民的饮水产生了极大威胁 ${ }^{[18-19]}$. 前期巢湖市政府对双桥河部分河道 进行了多次底泥疏浚工程, 其中最近一次底泥疏浚工程实施于 2017 年夏季. 通过控源手段削减了水体内外 源营养负荷, 短时间内改善了河流水质并维护了巢湖流域居民饮用水安全 ${ }^{[20]}$. 然而底泥疏浚工程对双桥河 水生生物群落结构及生物多样性的影响有待进一步研究, 其对水体生态系统的改善也尚有待评价. 本文通 过比较双桥河底泥疏浚前和疏浚后浮游甲壳动物的密度、生物量、生物多样性指数, 分析疏浚前后双桥河的 水质理化因子与浮游甲壳动物群落结构之间的关系, 从而探究底泥疏浚对河流浮游甲壳动物群落的影响以 及对富营养化河流生态修复的有效性.

\section{1 材料与方法}

\section{1 研究区域概况和采样点设置}

巢湖双桥河全长约 $7.3 \mathrm{~km}$, 流域总面积 $27 \mathrm{~km}^{2}$, 水质长期为劣 $\mathrm{V}$ 类. 河流上游为风凰之家河段, 上游来 水为双桥河的主要水源. 本研究在 2017 年夏季进行底泥疏浚的中游西炮营社区至下游人湖口, 长约 $4806 \mathrm{~m}$ 的河道内开展为期一年的河流生态监测和调查, 根据河道的走向和自然环境特点 (表 1) 设置 8 个采样点 (图 1). 在双桥河底泥疏浚前( 2017 年 6 月)、疏浚中(2017 年 9 月)、疏浚后(2017 年 12 月、2018 年 3 月) 分 别对双桥河疏浚区进行 4 次样品采集与分析.

表 1 双桥河河流特征值

Tab.1 Characteristic of river variables in Shuangqiao River

\begin{tabular}{ccccc}
\hline 时期 & 温度 $/{ }^{\circ} \mathrm{C}$ & 溶解氧 $/(\mathrm{mg} / \mathrm{L})$ & $\mathrm{pH}$ & 透明度 $/ \mathrm{cm}$ \\
\hline 疏浚前 & $30.67(29.00 \sim 31.00)$ & $7.24(4.50 \sim 8.20)$ & $9.43(8.37 \sim 10.87)$ & $31.25(19.00 \sim 58.00)$ \\
疏浚中 & $23.26(22.00 \sim 25.20)$ & $2.97(2.50 \sim 3.60)$ & $7.63(7.08 \sim 8.23)$ & $42.13(28.00 \sim 55.00)$ \\
疏浚后 & $13.52(6.90 \sim 20.90)$ & $9.64(5.10 \sim 18.40)$ & $8.11(7.97 \sim 8.29)$ & $46.00(32.00 \sim 57.00)$ \\
\hline
\end{tabular}

\section{2 水质理化指标分析方法}

水体透明度采用 Secchi 盘现场测定, 水体温度、pH、溶解氧浓度等使用 YSI 6600V2 型多参数水质监测 仪现场测定. 水体理化指标总氮 $(\mathrm{TN})$ 、总磷 $(\mathrm{TP})$ 、铵态氮 $\left(\mathrm{NH}_{4}^{+}-\mathrm{N}\right) 、$ 硝态氮 $\left(\mathrm{NO}_{3}^{-}-\mathrm{N}\right)$ 、可溶性氮 $(\mathrm{TDN}) 、$ 可溶 性磷 (TDP) 浓度等参照《水和废水监测分析方法》在实验室内测定 ${ }^{[21]}$.

\section{3 浮游生物采样方法和样品处理}

浮游甲壳动物定性样品采集时用 $13^{\#}$ 浮游生物网在河水中反复做“ $\infty$ ” 字型划水, 将其放人 $50 \mathrm{ml}$ 的塑 料小方瓶中, 加人 $4 \%$ 的甲醛溶液固定保存. 浮游甲壳动物定量样品采集时用 $5 \mathrm{~L}$ 的采水器在采样点取 $10 \mathrm{~L}$ 水样,之后用 $25^{\#}$ 浮游生物网过滤, 将其放人 $50 \mathrm{ml}$ 塑料小方瓶中, 用 $4 \%$ 的甲醛溶液固定保存. 每个季度在 8 个采样点各采集一次, 将样品带回实验室处理. 定性及定量样品均在 $10 \times 4$ 倍的显微镜下用 $5 \mathrm{ml}$ 浮游生物计 


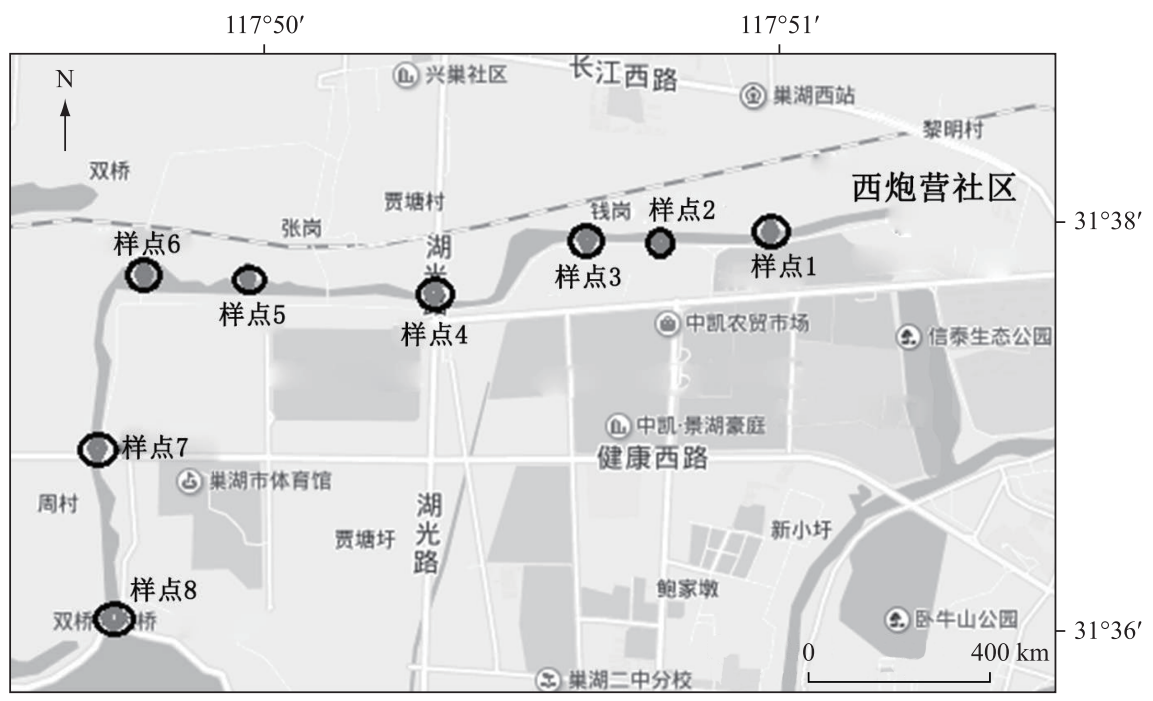

图 1 双桥河采样点分布 (样点 1 : 西炮营社区, 样点 2 : 潘岗桥, 样点 3 : 钱岗, 样点 4: 湖光路桥, 样点 $5:$ 水泥厂湿地, 样点 $6:$ 水泥厂桥, 样点 7: 健康西路桥, 样点 $8:$ 双桥河大桥)

Fig. 1 Distribution of sampling sites in Shuangqiao River

数板进行观察和计数. 其中, 浮游甲壳动物枝角类和桡足类按照 《中国动物志 (淡水枝角类) 》 ${ }^{[22]}$ 和《中国动 物志 (淡水桡足类) $\rangle^{[23]}$ 鉴定. 浮游甲壳动物生物量的估算参照陈雪梅 ${ }^{[24]}$ 、范正年 ${ }^{[25]}$ 等学者的方法.

\section{4 数据处理与分析}

浮游甲壳动物的多样性研究采用香农-维纳指数 (Shannon-Wiener index)、辛普森指数 (Simpson's diversity index) 和优势度指数:

$$
\begin{gathered}
H^{\prime}=-\sum_{i=1}^{r}\left(P_{i} \cdot \ln P_{i}\right) \\
D=1-\sum_{i=1}^{S} P_{i}{ }^{2} \\
Y=\frac{n_{i} \cdot f_{i}}{N}
\end{gathered}
$$

式中, $H^{\prime} 、 D$ 和 $Y$ 分别为香农-维纳指数、辛普森指数和优势度指数, $r$ 为种类数, $P_{i}$ 代表第 $i$ 种密度占总密度 的比例, $S$ 为物种数目, $D$ 值越大, 多样性越高. $n_{i}$ 为物种 $i$ 的密度, $f_{i}$ 为物种 $i$ 出现的频率, $N$ 为所有物种的总 密度. 实验数据经 Microsoft Excel 2010 和 SPSS 20.0 软件分析, 运用 Pearson 相关分析研究浮游甲壳动物与 水环境因子之间的相关关系.

\section{2 结果与分析}

\section{1 水体理化因子的变化}

底泥疏浚过程中, 双桥河的 $\mathrm{pH}$ 、溶解氧浓度呈先下降后上升趋势, 而透明度呈持续上升趋势 (表 1). 研 究期间, 双桥河未疏浚河段的氮、磷营养盐浓度随季节并无显著变化 (图 2). 而进行底泥疏浚工程的河段, 水体中 $\mathrm{N}$ 浓度呈显著下降后小幅上升趋势, 但疏浚后 $\mathrm{N}$ 浓度仍低于疏浚前. 其中 $\mathrm{TN}$ 浓度从疏浚前的 6.95 $\mathrm{mg} / \mathrm{L}$ 下降至疏浚后的 $3.61 \mathrm{mg} / \mathrm{L}$, 下降了 $48.09 \% ; \mathrm{NH}_{4}^{+}-\mathrm{N}$ 浓度从 $2.22 \mathrm{mg} / \mathrm{L}$ 下降至 $0.86 \mathrm{mg} / \mathrm{L} ; \mathrm{NO}_{3}^{-}-\mathrm{N}$ 浓度 从疏浚前的 $3.75 \mathrm{mg} / \mathrm{L}$ 下降至 $1.50 \mathrm{mg} / \mathrm{L} ; \mathrm{TDN}$ 浓度从 $6.14 \mathrm{mg} / \mathrm{L}$ 下降至疏浚后的 $3.02 \mathrm{mg} / \mathrm{L}$. 水体中 $\mathrm{P}$ 浓度 也呈下降趋势, 其中 TP 浓度呈显著下降后小幅上升趋势, 但疏浚后的浓度 $0.09 \mathrm{mg} / \mathrm{L}$ 仍低于疏浚前的 0.11 $\mathrm{mg} / \mathrm{L}$, 下降了 $19.09 \%$. TDP 的浓度疏浚后呈先上升后下降趋势, 从疏浚前的 $0.05 \mathrm{mg} / \mathrm{L}$ 先上升至疏浚中的 
$0.08 \mathrm{mg} / \mathrm{L}$, 后又下降至疏浚后的 $0.04 \mathrm{mg} / \mathrm{L}$, 疏浚后 的 TDP 浓度较疏浚前也有所下降(图 3).

\section{2 浮游甲壳动物的群落结构变化}

研究中,双桥河未疏浚河段共发现浮游甲壳动 物 13 种, 枝角类共 5 种, 桡足类共 8 种, 除夏季外,均 以桡足类为主. 疏浚河段共检测出浮游甲壳动物 17 种, 其中枝角类 8 种, 隶属 4 科 4 属, 占 $30.55 \%$, 桡足 类 9 种,隶属 4 科 7 属,占 $69.45 \%$ (表 2). 以优势度 $Y \geqslant 0.02$ 为标准, 通过计算优势度指数确定优势种. 优势种包括枝角类的微型裸腹溞 (Moina micrura) 和 短尾秀体溞 (Diaphanosoma brachyurum) , 桡足类的汤 匙华哲水蚤 (Sinocalanus dorrii)、广布中剑水蚤 $(M e-$

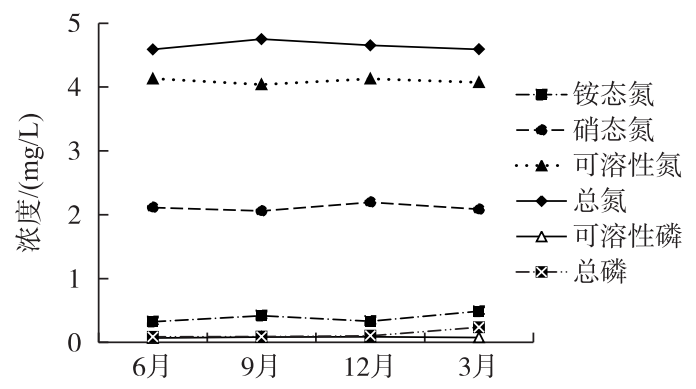

图 2 双桥河未疏浚河段氮、磷浓度年际变化

Fig. 2 Interannual variation of $\mathrm{N}$ and $\mathrm{P}$ concentrations in the undredging reach in Shuangqiao River socyclops leuckarti) 和台湾温剑水蚤 (Thermocyclops taihokuensis ). 根据优势度, 疏浚前浮游甲壳动物优势种依次为微型裸腹溞、汤匙华哲水蚤、短尾秀体溞和广 布中剑水虫; 疏浚中依次为微型裸腹溞、广布中剑水虫、台湾温剑水蚤、简弧象鼻溞( Bosmina coregoni)、长肢 秀体溞 (Diaphanosoma leuchtenbergianum) 、寡刺秀体溞(Diaphanosoma paucispinosum)、长额象鼻溞( Bosmina longirostris) 和球状许水蚤 (Schmackeria forbesi); 底泥疏浚后, 枝角类数量很少, 无优势种群, 浮游甲壳动物优 势种为广布中剑水蚤、中华窄腹剑水蚤 (Limnoithona sinensis) 和汤匙华哲水蚤 (图 4). 底泥疏浚工程后, 双桥 河浮游甲壳动物优势种由枝角类的微型裸腹溞向桡足类的广布中剑水蚤转变.
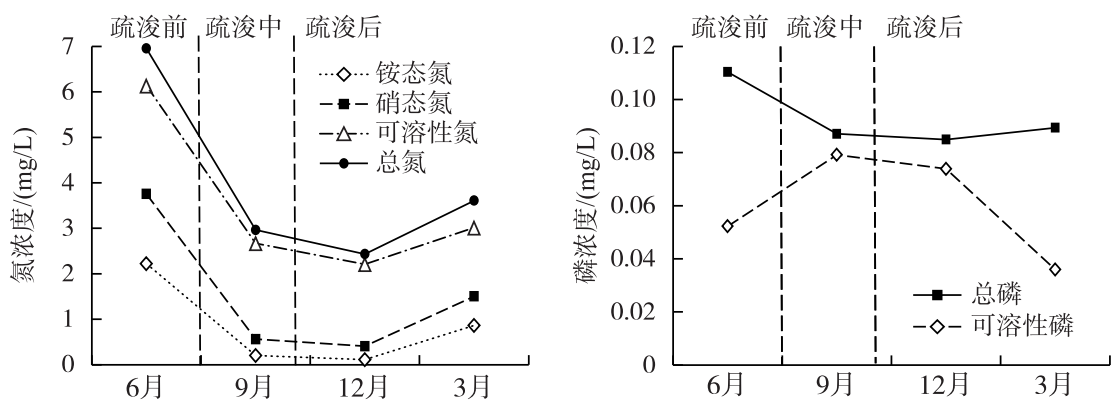

图 3 双桥河疏浚前与疏浚后氮、磷浓度比较

Fig. 3 Comparison of $\mathrm{N}$ and $\mathrm{P}$ concentrations in water of Shuangqiao River under pre-dredging and post-dredging conditions

\section{3 浮游甲壳动物生物量和密度的变化}

研究期间, 双桥河未疏浚段浮游甲壳动物平均密度为 $5.75 \mathrm{ind} . / \mathrm{L}$, 平均生物量为 $0.19 \mathrm{mg} / \mathrm{L}$. 底泥疏 浚河段浮游甲壳动物密度和生物量季节变化较大, 疏浚前、后数量差异显著 (图 5 ). 浮游甲壳动物平均密 度为 $137.00 \mathrm{ind} . / \mathrm{L}$, 其中枝角类平均密度为 $59.19 \mathrm{ind} . / \mathrm{L}$, 桡足类平均密度为 $77.81 \mathrm{ind} . / \mathrm{L}$. 底泥疏浚过程 中, 浮游甲壳动物的总密度最高为 $1096.00 \mathrm{ind} . / \mathrm{L}$, 总生物量为 $13.05 \mathrm{mg} / \mathrm{L}$. 疏浚后, 浮游甲壳动物密度下 降了 $58.85 \%$. 疏浚前, 浮游甲壳动物平均生物量为 $1.86 \mathrm{mg} / \mathrm{L}$, 疏浚中为 $0.51 \mathrm{mg} / \mathrm{L}$, 疏浚后为 $0.25 \mathrm{mg} / \mathrm{L}$, 疏浚后的浮游甲壳动物生物量下降了 $86.40 \%$. 疏浚前的枝角类平均生物量为 $1.61 \mathrm{mg} / \mathrm{L}$, 桡足类为 0.25 $\mathrm{mg} / \mathrm{L}$; 疏浚中枝角类的平均生物量为 $0.35 \mathrm{mg} / \mathrm{L}$, 桡足类为 $0.16 \mathrm{mg} / \mathrm{L}$; 疏浚后枝角类平均生物量为 0.03 $\mathrm{mg} / \mathrm{L}$, 桡足类为 $0.22 \mathrm{mg} / \mathrm{L}$. 其中疏浚前、后密度和生物量下降幅度最大的均为样点 2 , 分别下降了 $82.26 \%$ 和 92.09\% (图 6). 
表 2 双桥河疏浚段浮游甲壳动物季节变化及出现频率

Tab.2 Quarterly variation and occurrence frequency of crustacean zooplankton species on sediment dredging reach in Shuangqiao River

\begin{tabular}{|c|c|c|c|c|c|c|}
\hline 浮游甲壳动物 & & 6 月 & 9 月 & 12 月 & 3 月 & 出现频率 $/ \%$ \\
\hline \multirow[t]{8}{*}{ 枝角类 Cladocera } & 微型裸腹溞 Moina micrura & + & + & + & & 75 \\
\hline & 短尾秀体溞 Diaphanosoma brachyurum & + & + & & + & 75 \\
\hline & 长肢秀体溞 Diaphanosoma leuchtenbergianum & & + & & & 25 \\
\hline & 寡刺秀体溞 Diaphanosoma paucispinosum & & + & & & 25 \\
\hline & 角突网纹溞 Ceriodaphnia cornuta & + & + & & & 50 \\
\hline & 棘爪网纹溞 Ceriodaphnia reticulata & & + & & & 25 \\
\hline & 简弧象鼻溞 Bosmina coregoni & + & + & + & + & 100 \\
\hline & 长额象鼻溞 Bosmina longirostris & & & & + & 25 \\
\hline \multirow[t]{10}{*}{ 桡足类 Copepod } & 广布中剑水蚤 Mesocyclops leuckarti & + & + & + & + & 100 \\
\hline & 台湾温剑水蚤 Thermocyclops taihokuensis & + & + & + & + & 100 \\
\hline & 锯缘真剑水蚤 Eucylops serrulatus & & + & & + & 50 \\
\hline & 汤匙华哲水蚤 Sinocalanus dorrii & + & & + & + & 75 \\
\hline & 中华窄腹剑水蚤 Limnoithona sinensis & & & + & + & 50 \\
\hline & 绿色近剑水蚤 Tropocyclops prasinus & & & & + & 25 \\
\hline & 球状许水蚤 Schmackeria forbesi & + & + & + & + & 100 \\
\hline & 无节幼体 Nauplius & + & + & + & + & 100 \\
\hline & 桡足幼体 Copepodite & + & + & + & + & 100 \\
\hline & 合计/种 & 10 & 13 & 9 & 13 & \\
\hline
\end{tabular}
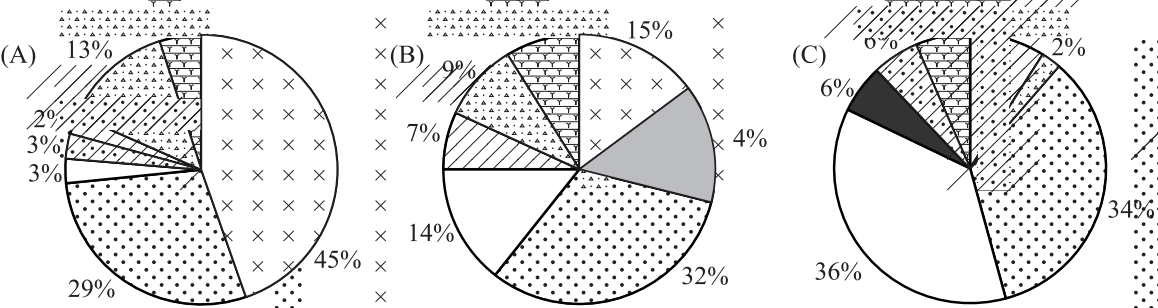

四广布中剑水蚤 园台湾温剑水蚤 无节幼体

$\square$ 桡足幼体

中华窄腹水虫 汤匙华哲水蚤

凶微型裸腹溞

短尾秀体渑

其他

图 4 双桥河疏浚前 $(\mathrm{A})$ 、疏浚中 $(\mathrm{B})$ 和疏浚后 $(\mathrm{C})$ 浮游甲壳动物群落结构对比

Fig.4 Comparison of crustacean zooplankton community structures in water of Shuangqiao River under pre-dredging ( A), dredging ( B ) and post-dredging ( C) conditions

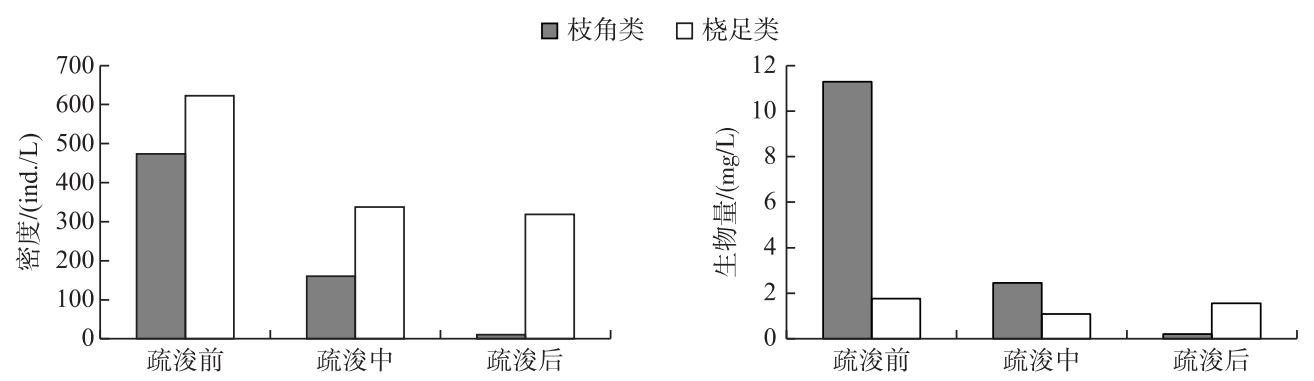

图 5 底泥疏浚各阶段双桥河浮游甲壳动物总密度和总生物量变化

Fig.5 Variation of quarterly total density and biomass of crustacean zooplankton on the various stages of sediment dredging in Shuangqiao River 


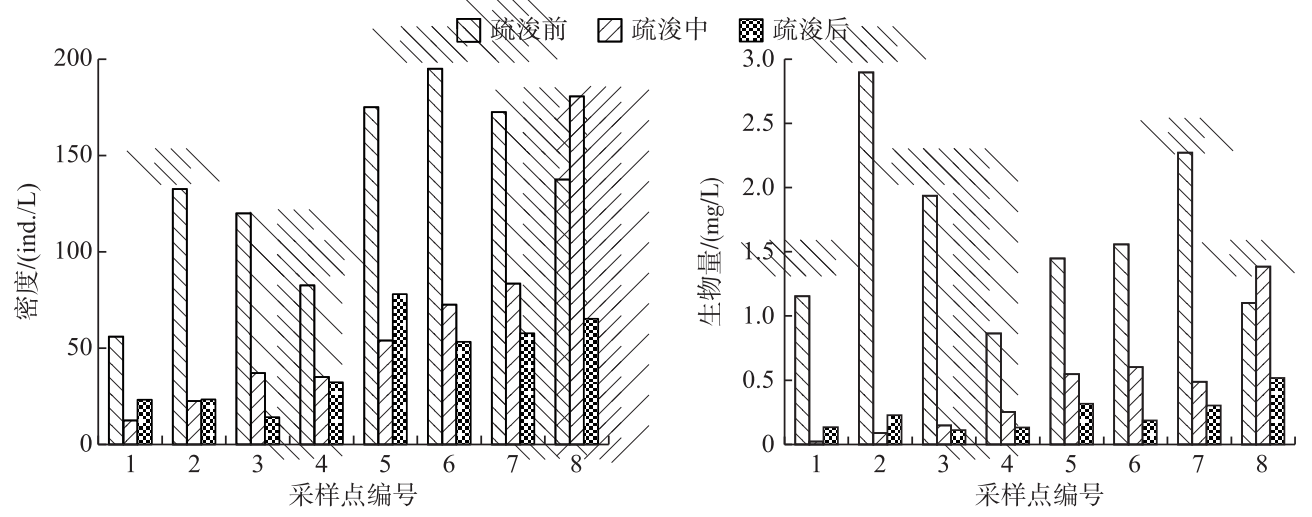

图 6 双桥河不同采样点的浮游甲壳动物密度和生物量

Fig.6 Spatial distribution of crustacean zooplankton density and biomass in Shuangqiao River

\section{4 浮游甲壳动物多样性指数}

通过计算浮游甲壳动物的 Simpson 指数和 ShannonWiener 指数, 并对其进行比较分析, 发现底泥疏浚后, 浮游 甲壳动物生物多样性指数均高于疏浚前 (图 7). Simpson 指数平均值为 0.68 , 其中疏浚前为 0.59 , 疏浚中为 0.77 , 疏 浚后为 0.67 . 各采样点间 Simpson 指数差异较大, 其中样点 2 疏浚前、后变化最大,从疏浚前的 0.24 上升至 0.75 (图 8). Shannon-Wiener 指数平均值为 2.09 , 其中疏浚前为 1.74 , 疏浚中为 2.63 , 疏浚后为 1.90 (图 7 ). 各采样点的生 物多样性指数差异较大, 其中 Shannon-Wiener 指数变化最 大的仍为样点 2 , 从疏浚前的 0.75 上升至疏浚后的 2.20 (图 8).

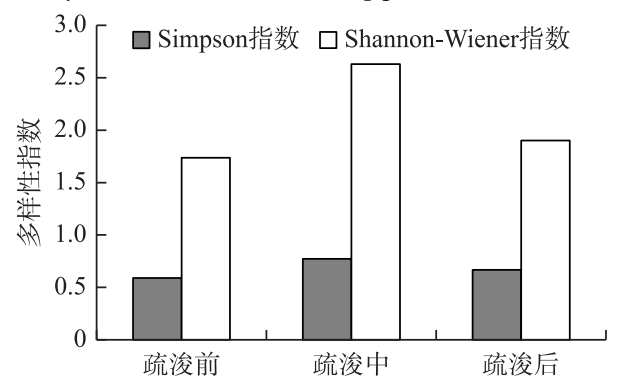

图 7 底泥疏浚各阶段双桥河浮游 甲壳动物多样性指数变化

Fig.7 Variation of diversity index crustacean zooplankton on the various stages of sediment dredging in Shuangqiao River

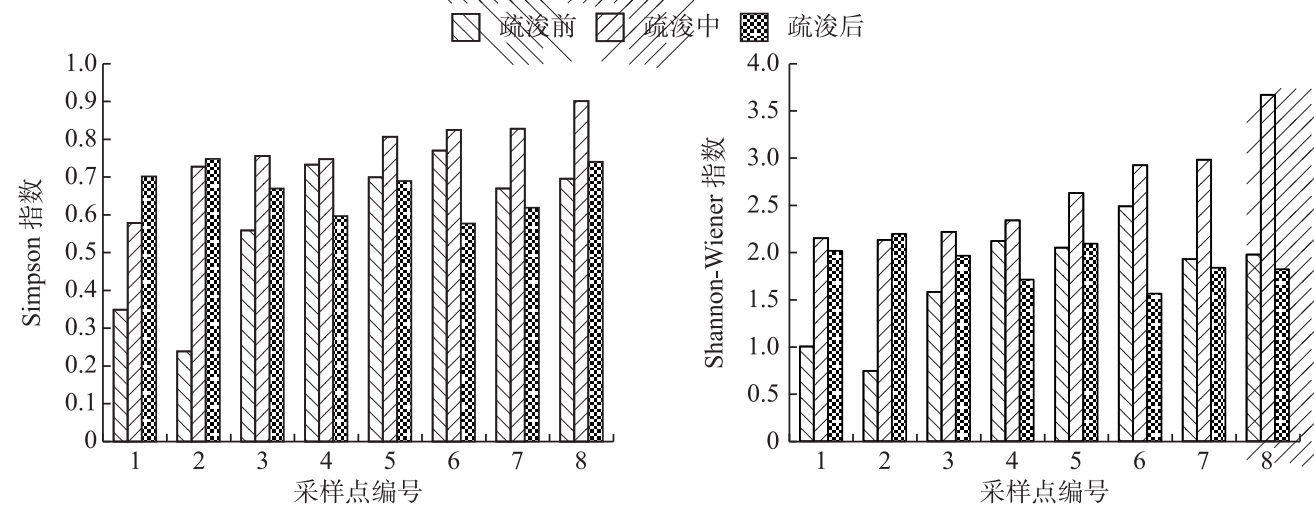

图 8 双桥河不同采样点的辛普森指数和香农-维纳指数对比

Fig. 8 Comparison of Simpson index and Shannon-Wiener index of crustacean zooplankton in different sampling sites of Shuangqiao River

\section{5 浮游甲壳动物群落结构与水环境因子相关性分析}

对浮游甲壳动物生物量与水环境因子进行 Pearson 相关性系数分析发现, 氮对浮游甲壳动物影响显著. 其中浮游甲壳动物的总生物量与 $\mathrm{pH}(r=0.571, P<0.01)$ 、温度 $(r=0.707, P<0.01) 、 \mathrm{NH}_{4}^{+}-\mathrm{N}$ 浓度 $(r=0.672, P<$ 
$0.01) 、 \mathrm{NO}_{3}^{-}-\mathrm{N}$ 浓度 $(r=0.742, P<0.01) 、 \mathrm{TDN}$ 浓度 $(r=0.701, P<0.01) 、 \mathrm{TN}$ 浓度 $(r=0.696, P<0.01)$ 、氮磷比 $(r=0.545, P<0.01)$ 呈极显著正相关. 枝角类生物量与 $\mathrm{pH}(r=0.698, P<0.01)$ 、温度 $(r=0.676, P<0.01)$ 、 $\mathrm{NH}_{4}^{+}-\mathrm{N}$ 浓度 $(r=0.753, P<0.01) 、 \mathrm{NO}_{3}^{-}-\mathrm{N}$ 浓度 $(r=0.793, P<0.01) 、 \mathrm{TDN}$ 浓度 $(r=0.781, P<0.01) 、 \mathrm{TN}$ 浓度 $(r=$ $0.780, P<0.01)$ 、氮磷比 $(r=0.572, P<0.01)$ 呈极显著正相关. 研究中, 并未发现桡足类生物量与某一水环境 因子呈显著相关关系 (表 3).

表 3 浮游甲壳动物生物量与水环境因子的 Pearson 相关性分析

Tab.3 Pearson correlation coefficient of planktonic crustaceans biomass and water quality parameters

\begin{tabular}{cccccccccc}
\hline 生物量 & $\mathrm{T}$ & $\mathrm{pH}$ & $\mathrm{NH}_{4}^{+}-\mathrm{N}$ & $\mathrm{NO}_{3}^{-}-\mathrm{N}$ & $\mathrm{TDN}$ & $\mathrm{TN}$ & $\mathrm{TDP}$ & $\mathrm{TP}$ & $\mathrm{N} / \mathrm{P}$ \\
\hline 枝角类 & $0.676^{* *}$ & $0.698^{* *}$ & $0.753^{* *}$ & $0.793^{* * *}$ & $0.781^{* *}$ & $0.780^{* *}$ & 0.009 & 0.178 & $0.572^{* * *}$ \\
桡足类 & 0.198 & $-0.367^{* *}$ & $-0.222^{* *}$ & $-0.101^{* *}$ & -0.194 & -0.212 & -0.251 & -0.033 & -0.153 \\
总生物量 & $0.707^{* *}$ & $0.571^{* *}$ & $0.672^{* *}$ & $0.742^{* *}$ & $0.701^{* *}$ & $0.696^{* *}$ & -0.026 & 0.104 & $0.545^{* *}$ \\
\hline
\end{tabular}

* 表示在 0.05 水平上显著相关 (双侧); **表示在 0.01 水平上显著相关 (双侧).

\section{3 讨论}

\section{1 底泥疏浚对双桥河水质的改善}

随着社会经济的发展, 大量的氮、磷营养盐直接人河导致河流富营养化日益严重 ${ }^{[26]}$. 研究期间, 双桥河 未疏浚河段营养盐浓度随季节并无显著变化, 这与前期研究的双桥河中氮、磷浓度随季节变化不大的结果 相一致 ${ }^{[27]}$. 同时, 此次双桥河的底泥疏浚工程对河流中氮、磷营养盐的释放具有一定的抑制作用. 其中水体 中 TN 和 TP 浓度分别下降了 $48.09 \%$ 和 19.09\%. 与前期双桥河底泥疏浚工程削减氮、磷营养盐的研究相比, 本研究中双桥河的 TN 和 TP 浓度远低于前期的研究, 同时 2017 年夏季的底泥疏浚工程对氮浓度削减幅度 较大, 这可能是由于多次的底泥疏浚工程已经大量削减底泥中氮、磷营养盐负荷且磷营养负荷削减较多造 成的 ${ }^{[18]}$. 本研究中 TN 浓度在疏浚后的半年内有小幅上升趋势, 这一结果与王广召等得到的疏浚两年后 (2012 年) 的双桥河 TN 浓度升高的结果相似 ${ }^{[20]}$. 这可能与河流的水一泥界面, 液态营养盐向上流通而固态 营养盐和总营养盐向下流通的规律有关 ${ }^{[5]}$. 在河流富营养状态没有完全改善的情况下, 周边生活污水的排 人使得水体表层有机碎屑和矿物质等细小颗粒很容易再次悬浮, 再次成为水体内污染源, 使得水体中的营 养盐浓度升高, 而河流富营养化很大程度上受制于营养盐的累积程度 ${ }^{[28]}$. 本研究中, 底泥疏浚工程尽管短 期内使得双桥河 TN、TP 浓度下降, 营养盐水平得到显著改善. 但疏浚后 TP 和 TN 浓度分别为 0.08 和 3.70 $\mathrm{mg} / \mathrm{L}$, 表明双桥河仍处于富营养化状态.

\section{2 底泥疏浚后双桥河浮游甲壳动物群落结构的变化}

此次研究中, 从空间上看, 双桥河上游浮游甲壳动物种类少, 以桡足类为主, 中下游疏浚河段种类多, 数 量大, 枝角类与桡足类所占比例相近. 从底泥疏浚不同阶段上看, 浮游甲壳动物种类数从疏浚前的 10 种上 升至疏浚后的 13 种, 出现了疏浚前没有的长额象鼻溞 (Bosmina longirostris) 、中华窄腹剑水蚤 (Limnoithona sinensis) 和绿色近剑水蚤 (Tropocyclops prasinus). 浮游甲壳动物优势种也发生了明显的变化, 作为富营养化 水体指示种的秀体溞在疏浚后并未作为枝角类的优势种出现可能是双桥河底泥疏浚后水质改善的反馈之 一. 从浮游甲壳动物密度和生物量的变化趋势上看, 底泥疏浚后的密度和生物量均有所下降. 同时研究中发 现不同采样月份间浮游甲壳动物密度和生物量差别较大, 这可能与双桥河氮磷浓度、温度和季节节律变化 有关 ${ }^{[28-29]}$. 底泥疏浚前期的夏、秋季水温较高, 浮游植物大量生长, 为浮游甲壳动物提供了充足的食物. 而底 泥疏浚后的冬、春季水温较低, 河流进人枯水期, 水体透明度低, 不利于浮游甲壳动物的生长 ${ }^{[30]}$. 就浮游甲 壳动物群落结构而言, 底泥疏浚后枝角类在浮游甲壳动物中的比重显著下降, 而桡足类所占比重显著上升. 这一结果与惠州西湖底泥疏浚后枝角类密度下降, 桡足类密度增加、在总生物量中的比重有所上升的结果 相似 ${ }^{[31]}$. 而与太湖梅梁湾和贡湖湾底泥疏浚后浮游甲壳动物群落结构不同的是 ${ }^{[32]}$, 双桥河枝角类生物量在 夏、秋季的底泥疏浚期间高于桡足类. 这可能是由于夏季底泥疏浚一定程度上抑制了蓝藻的生长, 降低了水 华蓝藻对枝角类的影响, 进而造成枝角类比重高于桡足类 ${ }^{[33-34]}$. 本研究表明双桥河的底泥疏浚工程能从一 
定程度上改善浮游甲壳动物群落结构, 促进河流水生生态系统向健康、安全的方向发展.

\section{3 底泥疏浚对双桥河浮游甲壳动物多样性指数的影响}

底泥疏浚后, 浮游甲壳动物的生物多样性指数均高于疏浚前. Simpson 指数和 Shannon-Wiener 指数分别 上升了 $14.63 \%$ 和 $12.33 \%$. 这说明底泥疏浚后, 在河流生态系统的结构和功能中发挥重要作用的浮游甲壳 动物群落结构有所改善. 作为水质指示动物, 在进行底泥疏浚后, $H^{\prime}$ 显著提高但并未达到清洁水体的标准 $\left(H^{\prime} \geqslant 4\right)$, 这也表明双桥河仍处于富营养化状态. 此外, 研究中各采样点间疏浚前、后生物多样性指数差异较 大, 如样点 2 的生物多样性指数前后变化最大, 疏浚后 Simpson 指数和 Shannon-Wiener 指数分别上升 $68.04 \%$ 和 $194.90 \%$. 这可能是因为在底泥疏浚前, 西炮营社区下游由于大量居民区污水和少部分工业废水直接排 人, 底泥中沉积了大量氮、磷营养盐, 造成水体生物多样性较低 ${ }^{[35]}$. 总体而言, 双桥河底泥疏浚工程可以有 效去除河流内源营养盐, 增加水生生物多样性, 使浮游甲壳动物生物多样性指数大幅度上升.

\section{4 底泥疏浚对环境因子与双桥河浮游甲壳动物群落之间关系的影响}

本次研究中疏浚河段浮游甲壳动物生物量与水环境因子的 Pearson 相关分析结果表明, 枝角类生物量 与双桥河河流中营养盐浓度特别是氮浓度呈极显著相关, 而桡足类生物量与水环境因子没有显著相关性. 双桥河底泥疏浚后, 河水中营养盐浓度特别是氮浓度大幅度降低可能是造成枝角类生物量下降的重要原因 之一 ${ }^{[12]}$. 这一结果与实验室研究得到的枝角类对磷的限制更加敏感, 而桡足类对氮的限制较为敏感的结果 有所不同, 可能与室内实验所用动物经过长期驯化有关 ${ }^{[36]}$. 底泥疏浚后浮游甲壳动物总密度和生物量分别 下降, 且生物量下降比例大于密度, 这反映出双桥河浮游甲壳动物呈现小型化趋势. 这与长春南湖底泥疏浚 削减氮、磷等营养盐后浮游动物趋于小型化的结果相似 ${ }^{[6]}$. 研究表明水体氮、磷等营养盐浓度降低会导致大 型枝角类的生长繁殖发生变化, 使得浮游甲壳动物群落结构发生改变. 如水体中的氮、磷等营养盐能改变浮 游甲壳动物的食性, 决定其机体的生长和繁殖 ${ }^{[37]}$. 底泥疏浚后, 随着水体中营养盐特别是氮浓度下降, 浮游 甲壳动物繁殖速度减缓, 而其密度和生物量均下降.

综合本研究结果, 底泥疏浚工程通过疏挖河流富含营养盐的上层底泥, 可有效地减轻双桥河的内源负 荷, 尤其是氮浓度的削减, 对水质的改善有积极作用. 底泥疏浚后双桥河浮游甲壳动物的群落结构有所恢 复, 种类有所增加, 原有的优势种也发生了改变. 但是, 河流生态系统较湖泊生态系统变化较快, 系统长期修 复更为复杂. 同时, 外源污水的输人使得双桥河成为城市污染控制型河流, 导致双桥河河段的营养盐浓度在 疏浚半年后出现了小幅上升. 因此, 仅依靠底泥疏浚工程并不能完全改善双桥河富营养化的局面. 在对双桥 河进行底泥疏浚的同时, 应该严格控制含氮污水的进人. 调整产业结构, 完善污水管网建设, 从而进一步恢 复水生生态系统, 更好地治理双桥河水体富营养化.

致谢: 中国科学院水生生物研究所的崔永德、张啸林等同志和安徽农业大学资源与环境学院的田昊䤧、李明 媛、王箫璇、王林、张寅生等同学协助了部分野外采样工作, 在此一并表示感谢!

\section{4 参考文献}

[ 1 ] Reddy KR, Fisher MM, Wang Y et al. Potential effects of sediment dredging on internal phosphorus loading in a shallow, subtropical lake. Lake \& Reservoir Management, 2007, 23(1) : 27-38.

[ 2 ] Liu HL, Cao XY, Song CL et al. Application of sediment dredging technology for restoration of eutrophic lakes. Environmental Pollution \& Control, 2012, 34(2) : 87-91, 101. [刘华丽, 曹秀云, 宋春雷等. 沉积物疏浚技术在富营养化湖 泊修复中的应用. 环境污染与防治, 2012, 34(2):87-91, 101.]

[ 3 ] Zhong J, Fan C, Zhang L et al. Significance of dredging on sediment denitrification in Meiliang Bay, China: A year long simulation study. Journal of Environmental Sciences, 2010, 22(1) : 68-75.

[ 4 ] Wang J, Liu XD, Lu J. Urban river pollution control and remediation. Procedia Environmental Sciences, 2012, 13(10): 1856-1862.

[ 5 ] Pu PM, Wang GX. Can we control lake eutrophication by dredging? J Lake Sci, 2000, 12(3) : 269-279. DOI: 10.18307/ 2000.0312. [誉培民, 王国祥. 底泥疏浚能控制湖泊富营养化吗? 湖泊科学, 2000, 12(3): 269-279.]

[ 6 ] Wang XY, Feng J, Li H. Research on variety of plankton community prior and post sediment dredging in Nanhu Lake, Changchun. Journal of Northeast Normal University: Natural Science Edition, 2005, 37(3): 90-94. [王小雨, 冯江, 李 
贺. 底泥疏浚前后长春南湖浮游生物群落变化研究. 东北师大学报: 自然科学版, 2005, 37(3) : 90-94.]

[ 7 ] Zhang SY, Zhou QH, Xu D et al. Effects of sediment dredging on water quality and zooplankton community structure in a shallow of eutrophic lake. Journal of Environmental Sciences, 2010, 22(2) : 218-224.

[ 8 ] Wu ZY, Yu ZM, Sheng HY et al. Ecological effects of the dredging in the West Lake, Hangzhou. J Lake Sci, 2008, 20 (3) : 277-284. DOI : 10.18307/2008.0303. [ 吴芝瑛, 虞左明, 盛海燕等. 杭州西湖底泥疏浚工程的生态效应. 湖泊 科学, $2008, \mathbf{2 0}(3): 277-284$. ]

[ 9 ] Ryding SO. Lake Trehörningen restoration project. Changes in water quality after sediment dredging. Hydrobiologia, 1982, 91/92(1) : 549-558.

[10] Murphy TP, Lawson A, Kumagai M et al. Review of emerging issues in sediment treatment. Aquatic Ecosystem Health \& Management, 1999, 2(4) : 419-434.

[11] Fan CX, Zhang L, Wang JJ et al. Process and mechanism of the influence of lake sediment dredging on endogenous release. Chinese Science Bulletin, 2004, 49(15) : 1523-1528. [范成新, 张路, 王建军等. 湖泊底泥疏浚对内源释放影 响的过程与机理. 科学通报, $2004,49(15): 1523-1528$. ]

[12] Tian X, Fu HC, Li Y et al. Seasonal dynamics of crustacean zooplankton community structure in Fujin National Wetland Park. Wetland Science, 2017, 15(1) : 73-79. [田雪, 付宏臣, 李宇等. 2015 年富锦国家湿地公园水体中浮游甲壳动 物群落结构及多样性季节动态. 湿地科学, 2017, 15(1) : 73-79.]

[13] Byron ER, Folt CL, Goldman CR. Copepod and cladoceran success in an oligotrophic lake. Journal of Plankton Research, $1984,6(1): 45-65$.

[14] Yang W, Deng DG, Zhang S et al. Seasonal dynamics of crustacean zooplankton community structure in Erhai Lake, a plateau lake, with reference to phytoplankton and environmental factors. Chinese Journal of Oceanology and Limnology, 2014, 32(5) : 1074-1082.

[15] Lampert W. Zooplankton research: the contribution of limnology to general ecological paradigms. Aquatic Ecology, 1997, 31 ( 1$)$ : 19-27.

[16] Yu JH, Zhong JC, Zhang YL et al. Simulation of influence of dredging on sediment resuspension and nutrient loading in lake. J Lake Sci, 2012, 24(1) : 34-42. DOI: 10.18307/2012.0105. [余居华, 钟继承, 张银龙等. 湖泊底泥疏浚对沉 积物再悬浮及营养盐负荷影响的模拟. 湖泊科学, 2012, 24(1) : 34-42.]

[17] Zhong JC, Liu GF, Fan CX et al. Environmental effect of sediment dredging in lake ( I ) : the role of sediment dredging in reducing internal phosphorous release. J Lake Sci, 2009, 21(1): 84-93. DOI: 10.18307/2009.0111. [ 钟继承, 刘国 锋, 范成新等. 湖泊底泥疏浚环境效应: I : 内源磷释放控制作用. 湖泊科学, 2009, 21(1):84-93.]

[18] Sima XF, Zhu WT, Fang T. Effect of dredging engineering on water environmental capacity of Shuangqiao River, Chaohu Lake. Chinese Journal of Environmental Engineering, 2012, 6(7): 2207-2214. [司马小峰, 朱文涛, 方涛. 疏浚对巢湖 双桥河水环境容量的影响. 环境工程学报, 2012, 6(7): 2207-2214.]

[19] Liu S, Kong FX, Cai YF et al. Nitrogen stable isotope study on nitrate nitrogen pollution of four in flowing rivers of Lake Chaohu. J Lake Sci, 2012, 24(6) : 952-956. DOI: 10.18307/2012.0619. [刘姝, 孔繁翔, 蔡元锋等. 巢湖四条人湖 河流硝态氮污染来源的氮稳定同位素解析. 湖泊科学, 2012, 24(6) : 952-956. ]

[20] Wang GZ, Fang T, Tang W et al. Long-term effects of dredging on pollutant distribution in sediments of a heavily polluted inflow river. J Lake Sci , 2014, 26(6) : 837-843. DOI: 10.18307/2014.0604. [王广召, 方涛, 唐魏等. 疏浚对巢湖重 污染人湖河流沉积物中污染物赋存及释放的影响. 湖泊科学, 2014, 26(6): 837-843.]

[21] Editorial board of "Water and wastewater monitoring and analysis method", Ministry of Environmental Protection of the People's Republic of China ed. Monitoring and analysis methods of water and wastewater: fourth edition. Beijing: China Environmental Science Press, 2002. [国家环境保护总局《水和废水监测分析方法》编委会. 水和废水监测分析方 法: 第 4 版. 北京: 中国环境科学出版社, 2002.]

[22] Fauna Editorial Committee Academia Sinica ed. Fauna Sinica Crustacea Freshwater Cladocera. Beijing: Science Press, 1979. [中国科学院中国动物志委员会. 中国动物志: 节肢动物门甲壳纲 淡水枝角类. 北京: 科学出版社, 1979.]

[23] Fauna Editorial Committee Academia Sinica ed. Fauna Sinica Crustacea Freshwater Copepod. Beijing: Science Press. 1999. [中国科学院中国动物志委员会. 中国动物志: 节肢动物门甲壳纲 淡水桡足类. 北京: 科学出版社, 1999.]

[24] Chen XM. Biomass calculation of freshwater Copepoda. Acta Hydrobiologica Sinica, 1981, 3: 397-408. [陈雪梅. 淡水桡 足类生物量的测算. 水生生物学报, 1981, 3: 397-408.] 
[25] Fan ZN. Comparison of two methods for determining freshwater cladocera biomass Chinese Journal of Zoology, 1988, 5: 32-34. [范正年. 测定淡水枝角类生物量的两种方法比较. 动物学杂志, 1988，5: 32-34.]

[26] Zhong CX, Zhang W. River engineering and ecological rehabilitation. Advances in Science and Technology of Water Resources, 2004, 24(3): 12-14. [ 钟春欣, 张玮. 基于河道治理的河流生态修复. 水利水电科技进展, 2004, 24(3): 12-14.]

[27] Xiao MC. Spatio-temporal distribution characteristic of nutrients in water of Lake Chaohu [Dissertation]. Wuhu: Anhui Normal University, 2015. [肖满成. 巢湖水体中氮磷营养盐时空分布特征研究 [学位论文]. 芜湖: 安徽师范大 学, 2015.]

[28] Nayar S, Miller DJ, Hunt A et al. Environmental effects of dredging on sediment nutrients, carbon and granulometry in a tropical estuary. Environmental Monitoring \& Assessment, 2007, 127(1/2/3) : 1-13.

[29] Sarma SSS, Nandini S, Gulati RD. Life history strategies of cladocerans: comparisons of tropical and temperate taxa. Hydrobiologia, 2005, 542(1) : 315-333.

[30] Liu BG, Liu X, Wu Y et al. Spatial and temporal distribution characteristics of planktonic crustaceans in Lake Poyang. Acta Ecologica Sinica, 2016, 36(24) : 8205-8213. [刘宝贵, 刘霞, 吴瑶等. 鄱阳湖浮游甲壳动物群落结构特征. 生态 学报, 2016, 36(24): 8205-8213.]

[31] Kang YH, Liu ZW, Zhang XF et al. Effects of sediment dredging on the metazoan zooplankton communities in a tropical shallow lake, Huizhou West Lake. Ecological Science, 2009, 28(3) : 247-252. [ 康玉辉, 刘正文, 张修峰等. 惠州西湖 底泥疏浚对后生浮游动物群落的影响. 生态科学, 2009, 28(3) : 247-252.]

[32] Li J, Wen ZR, Li GC et al. Relationship between crustacean zooplankton community structure and aquatic environmental factors of Meiliang and Gonghu Bay in Lake Taihu. Resources and Environment in the Yangtze Basin, 2014, 23(s) : 81. [李娟, 温周瑞, 李庚辰等. 太湖梅梁湾和贡湖湾浮游甲壳动物群落结构及其与环境因子的相互关系. 长江流域 资源与环境, $2014,23(\mathrm{~s}): 81$.]

[33] Bass JAB, Pinder LCV, Leach DV. Temporal and spatial variation in zooplankton populations in the River Great Ouse: an ephemeral food resource for larval and juvenile fish. River Research \& Applications, 1997, 13(3) : 245-258.

[34] Basu BK, Pick FR. Phytoplankton and zooplankton development in a lowland, temperate river. Journal of Plankton Research, 1997, 19(19) : 237-253.

[35] Yan DK, Huang Z. Current situation and countermeasures of water environmental pollution in Shuangqiao River of Chaohu Lake. Journal of Anhui Agricultural Sciences, 2017, 45(1): 76-78. [ 鄢达昆, 黄志. 巢湖双桥河水环境污染现状及防 治对策. 安徽农业科学, 2017, 45(1): 76-78.]

[36] Urabe J, Sterner RW. Contrasting effects of different types of resource depletion on life-history traits in Daphnia. Functional Ecology, 2001, 15(2): 165-174.

[37] Jeppesen E, Jensen JP, Søndergaard M et al. Trophic structure, species richness and biodiversity in Danish lakes: changes along a phosphorus gradient. Freshwater Biology, 2000, 45(2): 201-218. 